\title{
Novos sinônimos em Stachytarpheta (Verbenaceae) do Brasil
}

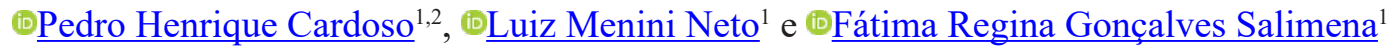

Recebido: 31 janeiro 2019; aceito: 15 agosto 2019

Como citar: Cardoso, P.H., Menini Neto, L. \& Salimena, F.R.G. 2019. Novos sinônimos em Stachytarpheta (Verbenaceae) do Brasil. Hoehnea 46: e082019. http://dx.doi.org/10.1590/2236-8906-08/2019.

ABSTRACT - (New synonyms in Stachytarpheta (Verbenaceae) from Brazil). During the taxonomic revision of Stachytarpheta (Verbenaceae) for the "Flora do Brasil 2020" project, we detected a high rate of overlap in morphological characters of related taxa, implying in a confusing circumscription and identification. Based on the morphological analysis of these taxa, review of the relevant literature and analyses of the type specimens and protologues, new synonyms are proposed for Stachytarpheta crassifolia.

Keywords: Duranteae, nomenclature, synonymization, taxonomy

RESUMO - (Novos sinônimos em Stachytarpheta (Verbenaceae) do Brasil). Durante a revisão taxonômica de Stachytarpheta (Verbenaceae) para o projeto "Flora do Brasil 2020" verificamos que alguns táxons apresentam alta taxa de sobreposição de caracteres morfológicos, o que dificulta a circunscrição e o reconhecimento dos mesmos. Com base na análise morfológica dos táxons, revisão da literatura especializada e análise dos tipos e protólogos, propomos novos sinônimos para Stachytarpheta crassifolia.

Palavras-chave: Duranteae, nomenclatura, sinonimização, taxonomia

\section{Introdução}

Stachytarpheta Vahl é um gênero com cerca de 130 espécies distribuídas nas Américas, Ásia, África e Oceania, cujo centro de diversidade é o Brasil (Atkins 2005). No país, são encontradas 82 espécies, das quais 75 são endêmicas, sendo a maioria restrita aos cerrados e campos rupestres dos Estados de Minas Gerais, Bahia e Goiás (BFG 2018). O gênero é monofilético, está incluído na tribo Duranteae, e apresenta como sinapomorfia morfológica a presença de androceu com dois estames férteis e dois estaminódios (Marx et al. 2010). Os principais estudos sobre Stachytarpheta são apresentados por Schauer (1847) que conduziu o tratamento clássico da família Verbenaceae e por Atkins (2005), na revisão do gênero para o Brasil.

Atkins (2005) reconheceu 12 grupos informais com base em caracteres morfológicos. O grupo "Cayennensis" é o mais diverso, compreendendo 19 espécies e sendo caracterizado por apresentar inflorescências de até 6 $\mathrm{mm}$ de largura e cálice imerso nas escavações da raque (Atkins 2005). A elevada sobreposição de caracteres diagnósticos entre alguns táxons desse grupo tem dificultado a delimitação, reconhecimento e a correta identificação, causando confusões taxonômicas.

Como parte da revisão taxonômica de Stachytarpheta para o projeto "Flora do Brasil 2020" (em construção), são propostos aqui novos sinônimos para S. crassifolia Schrad. O presente estudo está baseado na revisão da obra de Atkins (2005), consultas aos protólogos, tipos nomenclaturais ou imagens dos mesmos disponíveis em JSTOR Global Plants (https:// plants.jstor.org/) ou SpeciesLink (http://www.splink. org.br/), além da análise morfológica das coleções dos herbários CEN, CESJ, G, K, P, R, RB, SPF e W (acrônimos segundo Thiers 2018) e coleções virtuais (reflora.jbrj.gov.br/).

\section{Taxonomia}

Stachytarpheta crassifolia Schrad. TIPO: BRASIL. Rio de Janeiro: "prope praedium Paulista" [Lagoa do Paulista], IX-1815, Wied-Neuwied s.n. (lectótipo BR!, isolectótipo LE, designado por Moraes et al. 2013).

1. Universidade Federal de Juiz de Fora, Instituto de Ciências Biológicas, Campus Universitário, Rua José Lourenço Kelmer, s/n - São Pedro, 36036-900 Juiz de Fora, MG, Brasil

2. Autor para correspondência: pedro.cardoso@ecologia.ufjf.br 


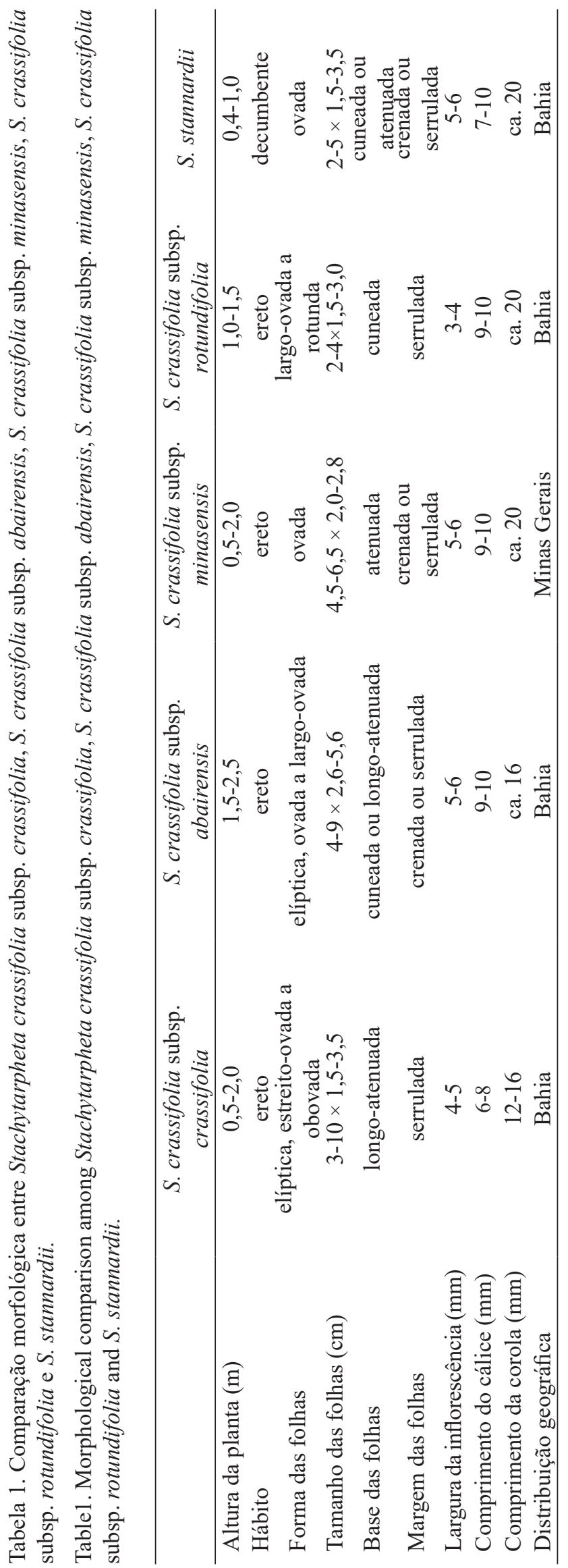

= Stachytarpheta crassifolia subsp. abairensis $\mathrm{S}$. Atkins. TIPO: BRASIL. BAHIA: Pico das Almas, 19-III-1977, R.M. Harley et al. 19683 (holótipo SPF!, isótipos CEPEC, $\mathrm{K}$ !, MO). syn. nov.

= Stachytarpheta crassifolia subsp. rotundifolia $\mathrm{S}$. Atkins. TIPO: BRASIL. BAHIA: Morro do Chapéu, 31-V-1980, R.M. Harley et al. 22831 (holótipo SPF!, isótipos CEPEC, K!, UEC, US imagem!). syn. nov.

= Stachytarpheta crassifolia subsp. minasensis $\mathrm{S}$. Atkins. TIPO: BRASIL. MINAS GERAIS: Jequitinhonha, 20-X-1988, R.M. Harley et al. 25235 (holótipo SPF!, isótipos E, K!, MO). syn. nov.

= Stachytarpheta crassifolia f. alba Moldenke. TIPO: BRASIL. BAhIA: Serra do Sincorá, 22-I-1984, G. Hatschbach 47464 (holótipo LL imagem!, isótipos CEPEC, HBG imagem!, MBM imagem!, SPF!, US imagem!). syn. nov.

= Stachytarpheta stannardii S. Atkins. TIPO: BRASIL. BAнiA: Abaíra, Riacho da Taquara, 28-I-1992, B. Stannard et al. 50835 (holótipo SPF!, isótipos CEPEC, HUEFS imagem!, K!). syn. nov.

Stachytarpheta crassifolia foi descrita com base na coleção de Wied-Neuwied s.n., cujo lectótipo depositado no Herbário BR foi designado por Moraes et al. (2013). Atkins (2005) estabeleceu três novas subespécies para $S$. crassifolia, pois considerou impossível englobar todas as variações morfológicas incluindo a forma e tamanho das folhas, largura da inflorescência e comprimento do cálice e da corola na circunscrição de um mesmo táxon. Entretanto, nenhuma das subespécies apresenta um caráter diagnóstico que permita claramente o seu reconhecimento e delimitação, sendo verificada grande sobreposição morfológica (tabela 1). Assim, admitindo a alta plasticidade fenotípica de $S$. crassifolia ao longo de sua distribuição é proposto o reconhecimento somente da categoria específica que inclui todas as variações encontradas neste táxon.

Atkins (2005) descreveu S. stannardii com base na coleção Stannard 50835 depositada no Herbário K. Endêmica do município de Abaíra, Estado da Bahia, esta espécie seria morfologicamente semelhante à S. crassifolia, mas diferindo por apresentar hábito decumbente, cálice ca. $10 \mathrm{~mm}$ compr. e tubo da corola ca. $20 \mathrm{~mm}$ compr. (versus hábito ereto, cálice 6-8 $\mathrm{mm}$ compr., e tubo da corola $12-16 \mathrm{~mm}$ compr. em $S$. crassifolia) (Atkins 2005). Os limites relacionados ao tamanho do cálice e corola claramente se sobrepõe ao de $S$. crassifolia que contempla cálice de 6-10 mm 
compr. e tubo da corola de 12-20 mm compr. (tabela 1). Tais caracteres referentes ao tamanho são frágeis para o estabelecimento de uma nova espécie em Stachytarpheta. Por sua vez, o hábito decumbente de $S$. stannardii está relacionado ao crescimento da planta em vertentes íngremes e fendas de rochas, e a ausência de informação sobre o hábito em etiquetas de herbário (que não é incomum), certamente levaria a identificação deste táxon como $S$. crassifolia, pois não existem outros caracteres morfológicos que separam essas espécies. Sendo assim, S. stannardii também pode ser considerada um sinônimo de $S$. crassifolia, a qual, além da alta sobreposição morfológica, é simpátrica com $S$. crassifolia.

\section{Literatura citada}

Atkins, S. 2005. The genus Stachytarpheta (Verbenaceae) in Brazil. Kew Bulletin 60: 161-272.
BFG (The Brazil Flora Group). 2018. Brazilian Flora 2020: Innovation and collaboration to meet Target 1ofthe Global Strategy for Plant Conservation (GSPC). Rodriguésia 69: 1513-1527.

Marx, H., O'leary, N., Yuan, Y., Lu-Irving, P., Tank, D., Múlgura, M.E., \& Olmstead, R. 2010. A molecular phylogeny and classification of Verbenaceae. American Journal of Botany 97: 1647-1663.

Moraes, P.L.R. de, Robbrecht, E., De Smedt, S., Dressler, S., Heinrichs, J., Reiner-Drehwald, M.H., Drescher, A., Scharfetter, A., Frödén, P., Esser, H.J., Gallagher, C., Guglielmone, L. \& Rainer, H. 2013. Catalogue of Brazilian plants collected by Prince Maximilian of Wied. Scripta Botanica Belgica 49: 1-249.

Schauer, J.C. 1847. Verbenaceae. In: A.L.P.P. Candole (ed.). Prodromus Systematis Naturalis Regni Vegetabilis. Victor Masson, Paris, pp. 522-700.

Thiers, B. 2018. Index Herbariorum: A global directory of public herbaria and associated staff. New York Botanical Garden's Virtual Herbarium. Disponível em http://sweetgum.nybg.org/ih/ (acesso em 28-XII-2018). 